\title{
Responsabilidade docente e violência na escola: rede de discursos que não se conectam com as estatísticas de desigualdade no Brasil
}

\author{
Bôer Possa, Leandra \\ Universidade Federal de Santa Maria, Santa Maria / RS, Brasil \\ leandrabp@gmail.com
}

Assis Brasil, Neffar Jaquelini Azevedo Vieira

Prefeitura Municipal de Alegrete,Alegrete / RS, Brasil

Universidade Federal de Santa Maria, Santa Maria, Brasil

jaqueliniassisbrasil@gmail.com

\section{Resumo}

O Estado brasileiro preocupado em produzir uma política inclusiva que se constitui de uma rede de proteção e garantia de direitos de crianças em adolescentes cria em 2004 um programa de financiamento para projetos, em todo território nacional, com as seguintes metas: a formação continuada de profissionais da educação pública de educação básica e a produção de materiais didáticos e paradidáticos que tratassem estrategicamente o enfrentamento da violência contra criançase adolescentes no contexto escolar. O programas echamou "Escola que Protege" e tinha como objetivo oferecer aos profissionais da educação a capacitação para atuarem diante de situações de violência no ambiente escolar. O programa atende a compromissos internacionais assumidos pelo Estado brasileiro e identifica a escola como instituição estratégica para uma culturados direitos de criançase adolescentes. Metodologicamente, este artigofo i construído pela triangulação de dados que se produziu pela análise discursiva: das metas do Programa Escola que Protege; e, de dados estatísticos sobre preconceito, pobreza e violência social no Brasil. Percebemos que o enfrentamento da violência na escola não pode ser considerada uma responsabilidade de profissionais da educação, apesar de estes terem um compromisso com mediações pedagógicas e educativas inclusivas e não violentas. Assim, concluímos que, o enfrentamento da violência na escola pública brasileira contra crianças e adolescentes não pode ser restrito a ações de formação dos profissionais da educação, tendo em vista que, seu campo de atuação não dá conta de responder sobre as relações complexas entre escola, sociedade e o governo constituído no Estado. Uma relação que em muitos momentos gera a própria violência a partir de modelos de desenvolvimento social-econômico e de modos como projeta, através das ações das instituições do Estado, o preconceito, a desigualdade e, com isso, a violência.

\section{Resumen}

El Estado brasileño preocupado en producir una política inclusiva que se constituye de una red de protección y garantía de derechos de niños en adolescentes crea en 2004 un programa de financiamiento para proyectos en todo el territorio nacional con las siguientes metas: la formación continuada de profesionales de la educación pública de educación básica y la producción de materiales didácticos y paradidáticos que tratase estratégicamente el enfrentamiento de la violencia contra niños y adolescentes en el contexto escolar. El programa se llamó "Escuela que Protege" y tenía como objetivo ofrecer a los profesionales de la educación la capacitación para actuar ante las situaciones de violencia en el ambiente escolar. El programa atiende a compromisos internacionales asumidos por el Estado brasileño e identifica a la escuela como institución estratégica para una cultura de los derechos de niños y adolescentes. Metodológicamente, este artículo fue construido por la triangulación de datos que se produjo por el análisis discursivo: de las metas del Programa Escuela que Protege; y de datos estadísticos sobre preconcepto, pobreza y violencia social en Brasil. Se percibe que el enfrentamiento de la violencia en la escuela no puede ser considerado una responsabilidad de profesionales de la educación, a pesar de que éstos tienen un compromiso con mediaciones pedagógicas y educativas inclusivas y no violentas. Así, concluimos que el enfrentamiento de la violencia en la escuela pública brasileña contra niños y adolescentes no puede ser restringido a acciones de formación de los profesionales de la educación, teniendo en vista que su campo de actuación no da cuenta de responder sobre las relaciones complejas entre escuela, sociedad y el gobierno constituidoenel Estado.Una relación que en muchos momentos genera la propia violencia a partir de modelos de desarrollo social-económico y de modos como proyecta, a través de las acciones de las instituciones del Estado, el prejuicio, la desigualdad y, con ello, la violencia. 


\section{Abstract}

The Brazilian State concerned with producing an inclusive policy that constitutes a network of protection and guarantee of children's rights in adolescents creates in 2004 a financing program for projects throughout the national territory, with the following goals: the continuous training of professionals of basic education public education and the production of didactic and para- educational materials that deal strategically with the confrontation of violence against children and adolescents in the school context. The program was called "School that Protects" and was intended to offer education professionals the ability to act in situations of violence in the school environment. The program meets the international commitments assumed by the Brazilian State and identifies the school as a strategic institution for a culture of the rights of children andadolescents. Methodologically, this article was constructed by the triangulation of data that was produced by the discursive analysis: of the goals of the School Program that Protects; and of statistical data on prejudice, poverty and social violence in Brazil. We realize that coping with violence at school can not be considered a responsibility of educational professionals, even though they have a commitment to inclusive and non-violent educational and educational mediations. Thus, we conclude that the confrontation of violence in the Brazilian public school against children and adolescents can not be restricted to training actions of education professionals, considering that their field of action does not respond to the complex relationships between schools, society and the government constituted in the State. A relationship that in many moments generates violence itself from models of social-economic development and ways in which it projects, through the actions of state institutions, prejudice, inequality and, with it,violence.

Palavras chaves: inclusão, desigualdade, formação de profissionais da educação; cenários de preconceito e violência.

Palabras clave: inclusión, desigualdad, formación de profesionales de la educación; escenarios de preconcepto y violencia.

Keywords: inclusion, inequality, training of education professionals; scenarios of prejudice and violence.

\section{INTRODUÇÃO}

Na redemocratização do Brasil, a partir da década de 80 , permitiu dar visibilidade, através da discussão política para diferentes grupos sociais e seus direitos. Sob a perspectiva da biopolítica, como um ação política pela normalização de uma forma de viver que todos possam ajustar-se e, ao mesmo tempo, serem regulados e controlados pela norma, torna-se importante conhecer quem são os grupos sociais que precisam ser narrados pelas políticas, vigiados pelas estatísticas, que precisam ser nomeados no âmbito político e que, até então, permaneciam sem serem descritos.

A criança, a família, a sociedade e o Estado são conclamados a viver e experimentar, a controlar um processo de desenvolvimento da infância e da adolescência que está conectado a um modo legitimado de ser da infância e da adolescência.

Este texto buscará analisar, em específico, um Programa educacional que foi construído no Brasil, o Escola que protege, em que observamos certa responsabilização da escola e dos professores com relação a violência contra crianças e adolescentes. No entanto, nesta análise também buscaremos mostrar que a violência produzida na escola, não pode ser uma responsabilidade somente da escola e dos professores (por mais bem formados que sejam) porque ela tem uma relação direta com a violência modulada e até estimulada modelos culturais, sociais e econômicos, baseados no preconceito, pobreza e violência social.

\section{CONTEXTO E DISCUSSÃO: POLÍTICAS, NORMAS E ESTRATÉGIAS}

No Brasil, a população de crianças e adolescentes passaram a serem narrados como um grupo social que tem direitos e que é passível de proteção social, a partir da Constituição de 1988. 
[...] à criança e ao adolescente, com absoluta prioridade, o direito à vida, à saúde, à alimentação, à educação, ao lazer, à profissionalização, à cultura, à dignidade, ao respeito, à liberdade e à convivência familia recomunitária, além de colocá-los a salvo de toda forma de negligência, discriminação, exploração, violência, crueldade e opressão [...] (BRASIL, 1988,s/p).

Os direitos das crianças e adolescentes expressos na Constituição Federal e, posteriormente organizados pelo Estatuto da Criança e do Adolescente (ECA) ${ }^{1}$, estavam vinculados ao debate dos Direitos Humanos, que como recomendações internacionais ${ }^{2}$, envolveram um conjunto articulado de ações governamentais e não-governamentais, e neste sentido, "As Redes de Proteção Integral compreendem todas as políticas públicas, serviços, instituições, órgãos e atores voltados para a garantia dos direitos da criança e do adolescente" (BRASIL, 2007, p. 09).

Nesse sentido, o ECA institui diretrizes para a política de atendimento, constituindo redes descentralizadas de proteção a través da municipalização do atendimento; da criação de conselhos e de programas específicos; da manutenção de fundos e da integração operacional de órgãos; da formação continuada de profissionais; da realização e divulgação de pesquisas sobre desenvolvimento infantil e sobre prevenção da violência; e da mobilização da opinião pública (BRASIL,1990).

No âmbito da Educação, a Secretaria de Educação Continuada, Alfabetização e Diversidade (Secad), criada em 2004, implementou ações com o foco na integração da escola às Redes de Proteção, principalmente, voltando-se à capacitação específica dos professores como forma de contribuir para o fortalecimento e para a ampliação das medidas de enfrentamento à violência, partindo do entendimento de que

[...] muitos educadores nãoestão ainda suficientemente preparados para identificaros casos de violênciae adotar as ações adequadas para seu enfrentamento. Diante disso, os processos de formação de profissionais que trabalham com e para crianças e adolescentes são absolutamente estratégicos [...] (BRASIL, 2007, p.39).

Dentre as ações, o Programa Escola que Protege vem sendo desenvolvido desde 2004, a partir do financiamento de projetos que visem atender as seguintes metas: a formação continuada de profissionais da educação pública de educação básica e a produção de materiais didáticos e para didáticos que tratam estrategicamente do enfrentamento da violência contra crianças e adolescentes no contexto escolar. Atualmente, o programa também faz parte das ações do Governo Federal que contemplamo Plano Nacional de Educação (BRASIL,2014), vinculado a estratégia:

7.23 Garantir políticas de combate à violência na escola, inclusive pelo desenvolvimento de ações destinadas à capacitação de educadores para detecção dos sinais de suas causas, como a violência doméstica e sexual, favorecendo a adoção das providências adequadas que promovam a construção da cultura de paz e um ambiente escolar dotado de segurança para a comunidade(BRASIL, 2014, s/p).

Neste texto, tomamos como referência o Programa Escola que Protege e os dados estatísticos do Brasil sobre preconceito, pobreza e violência social para analisar os discursos sobre a responsabilização docente no enfrentamento da violência naescola.

\section{METODOLOGÍA}

Estabelecer relações entre as metas, objetivos funcionamento, acompanhamento e avaliação do Programa Escola que Protege e alguns dados estatísticos ${ }^{3}$ nos remete a discutir como no cenário

\footnotetext{
${ }^{1}$ Lei n. ${ }^{\circ} 8.069$, de 13 de julho de 1990.

2 Declaração Universal dos Direitos Humanos, de 1948; Declaração dos Direitos da Criança, de 1959; Convenção Internacional sobre os Direitos da Criança e a Doutrina da Proteção Integral, de 1989.

${ }^{3}$ Do Instituto Brasileiro de Geografia e Estatística (IBGE) - Síntese de Indicadores Sociais 2017 - SIS 2017; Atlas da Violência (Ipea, 2017); Relatório Prova Brasil (2015); e, Ensino e Aprendizagem (TALIS), da OCDE.
} 
contemporâneo da educação brasileira o investimento na formação de profissionais da educação, especialmente dos professores, tem dimensionado uma forma de condução de condutas em que cada um e todos são responsabilizados, sob a perspectiva da economia de governo, a autogovernarem-se e a atuar no governo da conduta dos outros.

Ao apresentar os dados buscamos mostrar estratégias de sensibilização em que os próprios dados de preconceito, desigualdade, pobreza e violência são tratados como meio para que os próprios sujeitos se subjetivem e atuem no sentido de responsabilizarem-se. Um movimento em que é possível se compreender que, pela governamentalidade, tanto como razão quanto tática de governo, se descobre economicamente vantajosa para o Estado, porque seu principal alvo é a população (VEIGA-NETO, 2000). Governo e relações de poder para a constituição de condutas porque tecnologia útil na produção dos outros e de si mesmo (FOUCAULT, 1994) como empreendedores sociais e de si mesmo.

Uma economia de governo em que cada um e todos, no caso professores e instituições escolares passam, nas relações contemporâneas, assumir o papel de regulação e vigilância das condutas.

\section{DISCUSSÃO E CONCLUSÕES}

O Estado brasileiro preocupado em produzir uma política inclusiva que se constitui de uma rede de proteção e garantia de direitos de crianças em adolescentes cria, em 2004, um programa de financiamento para projetos, em todo território nacional: Escola que Protege. O objetivo do programa é prevenir e romper o ciclo da violência contra crianças e adolescentes, a partir da capacitação de profissionais para uma atuação qualificada em situações de violência identificadas ou vivenciadas no ambiente escolar. Dada a complexidade e abrangência do objetivo geral do projeto, o mesmo foi subdividido em objetivos específicos, de forma a possibilitar a montagem dos programas de capacitação. Assim, têm-se três objetivosespecíficos:

- Formar profissionais de educação para a identificação de evidências de situações de exploração do trabalho infantil, de violência física, psicológica, negligência e abandono, abuso e exploração sexual comercial contra crianças e adolescentes e enfrentamento no âmbito educacional, em uma perspectiva preventiva. - Sensibilizar e conscientizar a comunidade escolar sobre os prejuízos causados pelas diversas formas de violência (física, psicológica, sexual, negligência, abandono, exploração do trabalho infantil) no desenvolvimento bio-físico-psíquico-social das crianças, adolescentes e à família como um todo. - Estreitar as relações e integrar os sistemas de ensino ao fluxo de notificação e encaminhamento junto à Rede de Defesa, Responsabilização e Proteção à criança e adolescente (BRASIL, 2006, p. 06-07).

Nesse sentido, são priorizados o financiamento dos projetos apresentados por instituições que, por ações conjuntas e de responsabilidade compartilhadas, visem a formação continuada de profissionais da educação da rede pública de educação básica, além da produção de materiais didáticos e paradidáticos nos temas do projeto.

De acordo com o Manual do Programa (BRASIL, 2008a) os projetos deverão contemplar atividades de formação continuada de, no mínimo, 500 cursistas, com duração que varia entre seis e 12 meses, com carga horária mínima de 80 horas, sendo 60 horas presenciais e 20 horas a distância. De acordo com o regramento do programa, mais de $80 \%$ das vagas devem ser destinadas aos profissionais de educação, enquanto as demais, podem ser distribuídas entre profissionais de outras áreas.

Diante da prioridade dada a formação é obrigatório a elaboração e a apresentação, por parte dos cursistas, de um projeto de intervenção educacional no ambiente escolar como condição básica para a conclusão e certificação. Estes projetos precisam ter como objeto de ação o enfrentamento e prevenção da violência contra as crianças e adolescentes, conforme as instruções abaixo:

a. indicar prazo de início e término para sua execução: b) ter como foco o ambiente escolar; c) prever a participação da comunidade escolar (por exemplo, na elaboração ou revisão do Projeto Político-Pedagógico), do Grêmio Estudantil, dos Conselhos Escolares, bem como de outras instituições governamentais e organizações da sociedade civil envolvidas no enfrentamento e prevenção, no contexto escolar, das diferentes formas de violências contra a crianças e adolescentes; d) articular-se, sempre que possível, ao Projeto 
Pedagógico da Escola; e) visar enfrentar os desafios do cotidiano da escola, contemplando as condições materiais e as relações simbólicas que assegurem a promoção e garantia dos direitos de crianças e adolescentes; f) articular-se à Rede de Proteção em âmbito municipal, no sentido de investir na transformação de atitudes punitivas ligadas ao ato de educar (BRASIL, 2008a, p. 06-07).

Em relação à produção de materiais produção de materiais didáticos e paradidáticos, as "propostas deverão, obrigatoriamente prever a elaboração, edição e publicação de material [...] aplicável à sala de aula" (BRASIL, 2008a, p. 06). As propostas devem contemplar:

a. marcos legais, institucionais e conceituais necessários à compreensão do cenário nacional e internacional de enfrentamento da violência em suas diferentes formas, considerando os Planos Nacionais já mencionados; b) intersetorialidade das políticas públicas na abordagem e enfrentamento da violência;c) indicadores das violências contra crianças e adolescentes; d) estudos e pesquisas sobre os efeitos da violência contra crianças e adolescentes no rendimento e na exclusão escolar; e) Rede de Proteção e Garantia de Direitos de Crianças e Adolescentes e a ficha de encaminhamento de casos de violência contra crianças e adolescentes, conforme Manual constante do Anexo I; (Brasil, 2008b, s/p)

Aos materiais produzidos pelos cursistas são cadernos de atividades e manuais para o professor, fomentando recursos estratégicos na abordagem pedagógica do tema, de modo a mediar o trabalho junto aos alunos.

Para dar ordem a está dinâmica de formação são organizados dados sobre violência escolar, uma série de indicadores - índices de pobreza, escolaridade, rendimentos, taxas de homicídios, conflitos étnicos, raciais, questões de gênero, dentre outros - que mobilizam a atuação para a promoção da paz social e dos direitos humanos. Sobretudo, se articulam com estes dados a sensibilização dos profissionais para conduzirem suas condutas, para se responsabilizarem em pensar ações, se tornarem corresponsáveis, ou sejam, cada um e todos responsáveis.

Esta responsabilização via sensibilização, constitui-se num processo de subjetivação pela crença de uma ordem/norma que, embutida nas práticas discursivas sobre os índices de violência, fazem todos e cada criar o senso de responsabilidade; um efeito moral em que formar profissionais passa pela crença de que conhecer a realidade da violência, a ordem de ações capaz de diluir os focos de violência na escola é uma conduta necessária e que eles podem planejar e executar, traz a ideia de que esta violência pode ser diminuída, diluída e resolvida.

Esse processo de subjetivação presente nos processos de formação dos professores, nos leva a tensionar que nem tudo que parece é, de que esta ordem com a qual se produz uma verdade sobre a violência dirigida à crianças e adolescentes não pode ser tratada como um elemento simplificado, capaz de serem resolvidos pelos professores e escola, não se resumem a ações e projetos que estejam somente sob a responsabilidade deles.

Consideramos que esta ação interessada pela responsabilização da escola e dos professores não dilui a violência contra crianças e adolescentes no Brasil pois, mais que ações no campo educacional, é necessário perceber que os índices e dados do preconceito, da pobreza e da violência social e cultural não dependem de ações isoladas de cursistas em contextos escolares mas, de políticas públicas que vão muito além, sendo a escola e as relações de violência somente reflexo do que ainda precisa ser resolvido no âmbito da sociedade e do Estado.

Para argumentar no sentido de políticas mais multifacetárias para transformar as realidades escolares e a narrativa da violência produzida ou sofrida por crianças e adolescentes nos contextos escolares, trazemos alguns dados a seguir.

De acordo com os divulgados pela LCA Consultoria Econômica, em 2018, Villas Bôas afirma que o "[...] número de pessoas em situação de extrema pobreza no país passou de 13,34 milhões em 2016 para 14,83 milhões no ano passado, o que significa um aumento de 11,2\%" (VILLAS BÔAS, 2018, s/p). Pela pesquisa Síntese de Indicadores Sociais, em 2017 (SIS 2017), o maior índice de pobreza, no Brasil, se dá na Região Nordeste, onde $43,5 \%$ da população se enquadram nessa situação. A 
situação é ainda mais grave se levadas em conta as estatísticas do IBGE envolvendo crianças de 0 a 14 anos de idade. No país, $42 \%$ das crianças nesta faixa etária se enquadram nestas condições e sobrevivem com apenas US\$ 5,5 por dia (IBGE, 2017).

No que diz respeito à distribuição de renda no país, os dados da pesquisa SIS 2017 indicam que as taxas de desocupação da população preta ou parda foram superiores às da população branca em todos os níveis de instrução. Dentre as pessoas com os $10 \%$ menores rendimentos do país, a parcela da população de pretos ou pardos chega a $78,5 \%$, contra $20,8 \%$ de brancos. Também indicam que o percentual de jovens que não trabalham nem estudam aumentou 3,1 pontos percentuais entre $2014 \mathrm{e}$ 2016 , passando de $22,7 \%$ para $25,8 \%$, atingindo, sobretudo, os jovens com menor nível de instrução, negros ou pardos e as mulheres.

No que se refere a distribuição de renda Menezes e Januzzi (2018) com base nos dados do IBGE, 2017) afirmam:

[...] se for considerada a massa do rendimento mensal real domiciliar per capital, de $\mathrm{R} \$ 255,1$ bilhões, em 2016, verifica-se que os $10 \%$ da população com maiores rendimentos concentraram $43,4 \%$ desse total, ao passo que os $10 \%$ com menores rendimentos ficaram somente com $0,8 \%$. Em um país onde o rendimento médio mensal do trabalho, em 2016 , foi de $\mathrm{R} \$ 2.149,00$, esse grau de desigualdade fica mais nítido se for observado que o $1 \%$ de maior rendimento do trabalho recebeu em média, mensalmente, $\mathrm{R} \$ 27.085,00$, o que corresponde a 36,3 vezes daquilo que recebeu a metade de menor renda e, pior ainda, 371 vezes daquilo que receberam os 5\% de menor rendimento. (MENEZES; JANUZZI , 2018, s/p)

De acordo com o Atlas da Violência 2017 a população de jovens com menor nível de instrução, os negros ou pardos e as mulheres são as mais atingidas pela violência e desemprego, correspondendo $78,9 \%$ dos $10 \%$ dos indivíduos com mais chances de serem vítimas de homicídios. No mercado de trabalho, pretos ou pardos enfrentam mais dificuldades na progressão da carreira, na igualdade salarial e são mais vulneráveis a assédio moral (IPEA, 2017).

No que tange a dados específicos sobre a violência na escola, no Brasil, foram encontradas algumas informações referentes aos questionamentos respondidos por professores e diretores na Prova Brasil, organizados pelo portal de educação Qedu (2017). De acordo com o levantamento das respostas feito pelo portal, o corpo docente se depara com um ambiente hostil dentro das instituições, pois, mais de 22,6 mil professores foram ameaçados por estudantes e mais de 4,7 mil sofreram atentados à vida nas escolas em que lecionam. A maioria dos professores (71\%), o que equivale a 183,9 mil, também dizem ter ocorrido agressão física ou verbal de alunos a outros estudantes da escola (QEDU, 2017)

Já a pesquisa Internacional sobre Ensino e Aprendizagem (TALIS), coordenada pela OCDE, que investigou o ambiente de ensino e aprendizagem em escolas de educação básica de 34 países durante os anos de 2012 e 2013, apresentou alguns dados relacionados ao clima escolar, destacando questões como: vandalismo e furto; intimidação ou ofensa verbal entre alunos; danos físicos causados por violência entre alunos; intimidação ou ofensa verbal a professores ou membros da equipe escolar; uso/posse de drogas e/ou bebidas alcoólicas.

De acordo com a pesquisa, a intimidação ou ofensa verbal entre alunos ganha destaque nas escolas brasileiras, alcançando $34 \%$ dos índices. Também é interessante salientar que a grande maioria dos índices mais altos de frequência dessas situações concentram-se nos estados pertencentes as regiões Norte e Nordeste, o que também é destacado nos índices relativos à pobreza e baixa escolarização. Isso não quer dizer que nas outras regiões esses índices não tenham também relevância, pois "A miséria também cresceu na região mais rica do país, o Sudeste. De acordo com o levantamento da LCA, a região tinha 3,27 milhões de pessoas extremamente pobres no ano passado [2017], 13, 8\% a mais que no ano anterior" (VILLAS BÔAS, 2018, s/p).

A desigualdade social, a pobreza, a falta de perspectivas de vida frente aos modelos econômicos-sociais do consumo que, tem regido as relações de vida na contemporaneidade, as questões étnicas e de gênero, somadas ao modelo conservador e colonizador das maiorias baseado nos privilégios, chegam as portas da escola e adentram os espaços escolares. 
A violência, mais que uma relação que coloca em risco os modelos de pureza e obediência, podem ser considerados uma forma de resistência ou de caminho para acessar o que, por desejo e subjetivação, o próprio modelo de consumo tem gerado como modos de viver. Um modelo que inventa a possibilidade da supremacia e outras formas de exclusão legitimadas quando se utiliza da desigualdade ou de relações de saber e poder para nomear sujeitos que sofrem e praticam a violência.

Como conclusões provisórias, estes movimentos de investigação nos levam a considerar que, o enfrentamento da violência na escola pública brasileira contra ou praticada por crianças e adolescentes não pode ser restrito a ações de formação dos profissionais da educação, tendo em vista que, seu campo de atuação não dá conta de responder sobre as relações complexas entre escola, sociedade e o governo constituído no Estado. Uma relação que tem gerado, a partir de das escolhas de desenvolvimento social-econômico, modos de projetar o preconceito, a desigualdade a pobreza e, a partir do que elas geram, narrar a violência, os violentos e os que sofrem a violência.

\section{REFERÊNCIAS BIBLIOGRÁFICAS}

Brasil (1988). Constituição da República Federal do. Brasil. Brasília, DF: Senado Federal.

Brasil (1990). Lei n 8.069, de 13 de julho de 1990. Dispõe sobre o Estatuto da Criança e do Adolescente e dá outras providências. Brasília, DF, 1990.

Brasil (2006). Sumário Executivo Escola que Protege. Ministério da Educação Secretaria de Educação Continuada, Alfabetização e Diversidade (Secad/MEC).Brasília, DF.

Brasil (2007). Proteger para Educar: a escola articulada com as redes de proteção de crianças e adolescentes. Ministério da Educação Secretaria de Educação Continuada, Alfabetização e Diversidade (Secad/MEC). Brasília, DF.

Brasil (2008a). Manual do Projeto "Escola que Protege" para obtenção de apoio financeiro por meio do FNDE. Ministério da Educação Secretaria de Educação Continuada, Alfabetização e Diversidade (Secad/MEC). Brasília, DF.

Brasil (2008b). Resolução n 37 de 22 de julho de 2008. Estabelece orientações para a apresentação, a seleção e o apoio financeiro a projetos de instituições públicas de educação superior e da Rede Federal de Ensino Profissional e Tecnológico (com educação superior) para a formação continuada de profissionais da educação da rede pública de educação básica voltados para o enfrentamento, no contexto escolar, das diferentes formas de violências contra crianças e adolescentes. Fundo Nacional de Desenvolvimento da Educação (FNDE). Brasília, DF, $2008 \mathrm{~b}$.

Brasil (2009). Resolução no 17 de 08 de abril de 2009. Anexo II - Lista de municípios prioritários. Brasília, DF, 2009.

Brasil (2014). Lei n 13.005, de 25 de junho de 2014. Aprova o Plano Nacional de Educação - PNE e dá outras providências. Brasília, DF, 2014.

Foucault, M. (1994). As técnicas de si. Foucault, M. Dits et écrits. Paris: Gallimard, 1994, Vol. IV, pp. 783-813.

Instituto Brasileiro de Geografia e Estatística (2017). Síntese de Indicadores Sociais: uma análise das condições de vida da população brasileira - 2017. Coordenação de População e Indicadores Sociais. - Rio de Janeiro: IBGE. Disponível em <https://biblioteca.ibge.gov.br/visualizacao/livros/liv101459.pdf>.

Instituto de Pesquisa Econômica e Aplicada IPEA (2017). Atlas da Violência 2017. Instituto de Pesquisa Econômica Aplicada. Fórum Brasileiro de Segurança Pública. Rio de Janeiro. Disponível em: <http://www.ipea.gov.br/portal/images/170602_atlas_da_violencia_2017.pdf>.

QEDU. Portal de Educação. (2015). Pessoas da Comunidade Escolar: Brasil. Disponível em <https://www.qedu.org.br/ brasil/pessoas>.

Menezes, F. \& Januzzi, Paulo. (2018). Com o aumento da extrema pobreza, Brasil retrocede 10 anos em dois. Rede Brasil Atual, Ed de 26 de março de 2018. Disponível em: <http://www.redebrasilatual.com.br/cidadania/2018/03/ com-o-aumento-da-extrema-pobreza- brasil-retrocede-dez-anos-em-dois>. 
Veiga-Neto, A. (2000). Educação e governamentalidade neoliberal: novos dispositivos, novas subjetividades. In Portocarrero, V.; Branco, G. C. (org.) Retratos de Foucault. Rio de Janeiro (RJ): Nau, 2000, p. 179-217.

Villas Bôas, B. (2018). Pobreza extema aumenta 11\% e atinge 14,8 milhões de pessoas. Rio de Janeiro: Valor Econômico, Ed 12 de abril de 2018. Disponível em:<http://www.valor.com.br/brasil/5446455/pobreza-extrema-aumenta-11-e-atinge-148-milhoes-de- pessoas>. 